\title{
Health Risks of Passive Smoking
}

\author{
Cheri M. Papier, MPH, MS \\ Steven D. Stellman, PhD
}

\begin{abstract}
Passive or involuntary smoking is the inhalation of smoke which escapes directly into the air from the lit end of a burning cigarette. This unfiltered smoke contains the same toxic components of the mainstream smoke inhaled directly by the smoker, including numerous carcinogens, many in greater concentrations. It has long been known that exposure to this type of smoke leads to increased respiratory and other adverse health conditions in non-smokers, especially children. During the past five years, evidence has been accumulating that risk of lung cancer is also higher, particularly in non-smoking women whose husbands smoke. Despite uncertainties and differences in interpretation of various cancer studies, there is ample justification for public health measures now in place or proposed, such as restriction or elimination of smoking in the workplace and in public places.
\end{abstract}

\section{INTRODUCTION}

Use of tobacco ranks as one of the most serious health problems among American women. Elsewhere in this issue Virginia Ernster has pointed out that cigarette smoking accounts for over 50,000 deaths per year from cancer of the lung, larynx, esophagus, bladder, and other sites (Ernster, 1986), and Deborah Winn and Linda Pickle recount the evidence linking cancer of the mouth with use of smokeless tobacco, such as snuff (Winn and Pickle, 1986).

Both the Ernster and Winn-Pickle papers deal with the lethal effects of tobacco on the woman who uses it. It is increasingly recognized that tobacco use can harm others besides those who consume it directly. This paper summarizes the effects on individuals of exposure to the cigarette smoke of others, with particular attention

Cheri M. Papier is with the Department of Preventive and Social Medicine, Sackler School of Medicine, Tel Aviv University, Tel Aviv 69978 Israel. Steven D. Stellman is Assistant Vice President for Epidemiology, American Cancer Society, 4 West 35th Street, New York, NY 10001. 
to possible increase in cancer risk to adult women exposed to the cigarette smoke of others, but who are not themselves smokers.

Non-cancer effects are also briefly mentioned, especially on children and the unborn, in order to emphasize the secondary impact on women, who are primarily responsible for protecting the health of their offspring and caring for them when sick (see also papers by Feldman and Hach in this issue); they are also mentioned to demonstrate that passive smoking carries with it well-established health risks for outcomes other than cancer. These other outcomes have been under investigation for several decades, whereas the earliest cancer study was published only five years ago (Hirayama, 1981). Thus, formal investigation of passive smoking and cancer is not as mature a field as other areas of epidemiological investigation.

While methodological uncertainties do not yet permit the absolutely firm conclusion that passive smoking causes cancer in those exposed, evidence in that direction continues to accumulate. The quality of this evidence, even in its currently incomplete state, leaves no doubt about the propriety of public health measures intended to reduce the risks to non-smokers. These administrative measures will also be discussed below.

\section{WHAT IS PASSIVE SMOKING?}

Passive smoking, sometimes called involuntary or second-hand smoking, is the inhalation of smoke given off by a burning cigarette, and can result merely from being in the presence of a smoker. Its harmfulness is related to the distinction between mainstream and sidestream smoke. The smoker, of course, is always exposed to mainstream smoke; this emanates from the burning tip of the cigarette and passes through the as-yet unburned tobacco and the cigarette's filtration system before being absorbed in the smoker's respiratory system.

Non-smokers and smokers alike, on the other hand, are both exposed to the sidestream smoke. This is the unfiltered smoke which rises from the lit end of the burning cigarette, whether held in the smoker's mouth or resting untouched in an ashtray. It also includes the smoke exhaled by the smoker.

Sidestream smoke contains most of the toxic components of mainstream smoke, but at significantly higher concentrations. The ratios of sidestream to mainstream concentrations of some of these 
components have been reported as: ammonia, 73; methylnaphthalene, 28; aniline, 30; benzo(a)pyrene, 3 (USDHEW, 1979); carbon monoxide, 6.8; nicotine, 6.6; tar, 3.5 (Rickert et al., 1984). These ratios are typical of those for many other toxic compounds found in tobacco smoke, such as pyridine, carbon dioxide, acetone, and oxides of nitrogen. Sidestream smoke is also rich in known carcinogens, such as benzene, benz(a)anthracene, and a variety of nicotine-derived nitrosamines (Brunnemann and Hoffmann, 1978). Formaldehyde and acrolein, two components of tobacco smoke which cause eye and nasal irritation, have been found in sidestream smoke at concentrations up to three orders of magnitude above the limit for occupational exposure (Ayer and Yaeger, 1982).

Precise estimation of the degree of individual exposure to sidestream smoke is extremely difficult to make. Exposure to passive smoking depends on the number and type of cigarettes smoked, the room size, degree of ventilation, and smoke residence time. Carefully controlled studies with non-smoking volunteers exposed to sidestream smoke however, have firmly established measurable elevation of both nicotine and cotinine (its major metabolite) in saliva and urine and of cotinine in plasma (Hoffmann et al., 1984). Cotinine concentrations measured in the saliva of school children were strongly correlated with their parents' smoking habits (Jarvis et al.,1985). Such biological monitoring is both difficult and expensive, and cannot provide estimates of exposures in the past. Therefore, much cruder indexes of exposure in the home or work environment must be used in epidemiological studies.

The extent of exposure in specific populations is difficult to measure, and only limited estimates are available. Friedman and colleagues tabulated questionnaire responses of over 37,000 nonsmokers and former smokers who received multiphasic health checkups in 1979 and 1980 through the Kaiser-Permanente Medical Care Program (Friedman et al., 1983). They reported exposure for at least one hour per week in $63.3 \%$ of subjects, at least ten hours per week in $34.5 \%$, and exposure of more than 40 hours per week in $15.9 \%$ of their subjects.

Even without direct measurements, it can be assumed that significant exposures occur in people's homes, especially to children. Bonham and Wilson (1981) found that $62 \%$ of U.S. homes with children in 1970 contained one or more smokers, and $25 \%$ contained two or more. It must therefore be assumed that large numbers of children are exposed to passive smoke in their own homes. 


\section{HEALTH RISKS FROM PASSIVE SMOKING}

Studies of health effects of passive smoking have appeared with increasing frequency since the early 1960s, and now comprise a substantial literature. Even before cancer was suspected as a possible consequence of passive smoking, effects on reproduction and child growth had already been established. For example, babies of smoking mothers weigh an average of $200 \mathrm{~g}$ less than those of non-smoking mothers (USDHEW, 1979, p. 8-11; Butler et al., 1972). Higher rates of fetal loss (spontaneous abortion and stillbirth) have been observed in smoking mothers compared to non-smoking mothers (Goujard et al., 1975; Himmelberger et al., 1978; Stein and Kline, 1973). Higher rates of neonatal and perinatal deaths, as well as sudden infant death syndrome, have been reported (Comstock et al., 1971; Kullander and Kallen, 1971). Effects of smoking on the unborn have been reviewed in Surgeon-General's reports (USDHEW, 1979; USDHHS, 1980) and by McIntosh (1984).

Nursing babies are exposed to their mother's cigarette smoke via breast milk as well as in the air (Trundle and Skellern, 1983). Infants exposed to tobacco smoke absorb enough of its constituents to make measurement of urinary cotinine a reliable measure of such exposure (Greenberg et al., 1984). Children of smoking parents have higher rates of pneumonia, bronchitis, and other respiratory symptoms (Lebowitz and Burrows, 1976; Ware et al., 1984; Schenker et al., 1983; Charlton, 1984). They experience higher hospital admission rates for these conditions than do children of non-smoking parents (Harlap and Davies, 1974).

Non-smoking adults also experience conditions resulting from passive inhalation. Reported effects include eye, nose, and throat irritation (Weber, 1984), headaches, dizziness, and nausea (Shephard et al., 1979), aggravation of allergies and asthma (Knight and Breslin, 1985), and impairment of lung function (Kauffmann et al., 1983).

\section{PASSIVE SMOKING AND CANCER IN ADULT WOMEN}

An association between lung cancer in women and exposure to their husbands' cigarette smoke was first reported by Hirayama (1981). In a prospective study, Hirayama found approximately a 
two-fold increase in risk for Japanese women whose husbands smoked a pack or more per day. A case-control study done in Greece appeared at about the same time in which a relative risk of 3.4 was found for wives of men who smoked over 20 cigarettes per day (Trichopoulos et al., 1981, 1983), and an American case-control study reported similar findings (Correa et al., 1983). In all three of these studies there was evidence of a dose-response relationship, based upon varying definitions of dosage.

Since the appearance of those three studies, a number of other investigations have been undertaken. Not all of these later studies confirmed the smoking-lung cancer link with the same degree of consistency as the first three. In the American Cancer Society's 25-state prospective study the rate of lung cancer in women married to husbands who smoked was 1.2 times that of women married to non-smokers; this increase was not statistically significant (Garfinkel, 1981). Kabat and Wynder (1984) reported an association for men but not women exposed to passive smoke at work, and no effect in either wives or husbands exposed to their spouses' smoke. Other studies have reported significant (Garfinkel et al., 1985; Sandler et al., 1985a,b), borderline (Koo et al., 1983) and non-significant results (Chan, 1982; Wu et al., 1985), respectively. In one of the strongest positive studies, Garfinkel et al. (1985) identified 134 cases of lung cancer and 402 controls with colo-rectal cancer from hospital records in New Jersey and Ohio. All were non-smoking women. The relative risk for lung cancer was 2.11 for women whose husbands smoked 20 or more cigarettes per day at home, compared to wives of non-smoking husbands.

Because of the obvious social and economic implications that would result from acceptance of the causal nature of these associations by the scientific-medical community, all passive smoking studies have been subjected to unusually intense scrutiny, and have been heavily criticized for possible methodological shortcomings. In the most extreme case, the president and director of statistics from The Tobacco Institute (U.S.A.) interpreted a trivial arithmetic discrepancy as a "grave" error which raised "serious questions about the study." Other, more credible questions have been raised, and a lively discussion has appeared in the medical literature (Kornegay et al., 1981; Tsokos et al., 1981; Repace, 1984).

The controversy centers mainly about the extreme difficulty of defining exposure or dosage in a meaningful way. For instance, Garfinkel and colleagues found no association when the dosage 
variable was hours per day of exposure, either during the past 5 or the past 25 years. An equally important finding was that $40 \%$ of women with lung cancer initially identified through hospital records as non-smokers or with smoking status unknown turned out to be smokers at some time during their lives, according to interviews. Another $13 \%$ did not have primary lung cancer (Garfinkel et al., 1985). Such misclassification is a major potential source of difficulty in passive smoking studies, and could easily dilute or completely obscure a real effect. These and related problems may be responsible for the lack of consistency in studies published to date.

\section{PUBLIC HEALTH MEASURES FOR REDUCING RISKS FROM PASSIVE SMOKING}

In the United States today a major effort is under way to reduce the opportunities for passive exposure to cigarette smoke. This effort began as a movement by non-smokers for the right to breathe clean air and was based originally on reports of eye, nose, and throat irritations, headaches, nausea, dizziness, respiratory congestion and other so-called "minor irritations." It has achieved widespread support and gained considerable momentum, so that today the activities of many organizations involve this issue.

The most widespread activity is the establishment of so-called Clean Indoor Air legislation on state and local levels. As of January, 1986, at least eleven states, ten counties, and more than 30 municipalities had some form of legislation in effect. For instance, smoking in both private and governmental workplaces is restricted in Connecticut, Florida, Maine, Minnesota, Montana, Nebraska, New Jersey, and Utah. Restrictions on smoking in governmental workplaces were enacted in Alaska, California, and Hawaii. Local codes govern workers in San Francisco, and Nassau and Suffolk Counties, New York.

The success of clean air legislation is due to the combined efforts of numerous private and public organizations. A major stimulus to this legislative activity is provided by the National Coalition on Smoking Or Health, which includes the American Cancer Society, American Heart Association, and American Lung Association. Smaller organizations also play key roles, including the California Non-Smokers' Rights Foundation, ASH (Action on Smoking and Health), and GASP (Group Action against Smoking Pollution). Be- 
cause of the activities of these and other groups, clean air legislation either exists or has been introduced in nearly every state. In addition, a growing number of private businesses now restrict areas where employees may smoke. These firms include Pacific Northwest Bell, Stride Rite Corp., and Boeing Corp.

A second strategy to assert non-smokers' rights to breathe clean air involves direct lawsuits against employers. In 1976, Donna Shimp, an employee of New Jersey Bell Telephone Company, obtained a court injunction ordering Bell to provide a workplace free of cigarette smoke for its non-smoking employees (Shimp v. New Jersey Bell Telephone Company, New Jersey Superior Court, Chancery Division, Para. 21, 421, December 20, 1976). The Court stated in its ruling

... The company already has in effect a rule that cigarettes are not to be smoked around telephone equipment. The rationale behind this rule is that the machines are highly sensitive and can be damaged by the smoke. Human beings are also very sensitive and can be damaged by cigarette smoke . . . A company that has demonstrated such concern for its mechanical components should have at least as much concern for its human beings.

Other lawsuits have achieved varying degrees of success, but as a general strategy, litigation is extremely limited, as it is very expensive, can last for years, and is subject to reversal upon judicial review. A specific decision, moreover, can be interpreted so narrowly as to affect only the individual litigant.

\section{RESPONSE OF THE TOBACCO INDUSTRY TO PASSIVE SMOKING CANCER STUDIES}

The popularity of legislative and other approaches to limiting passive exposure to cigarette smoke has provoked a range of responses from the tobacco industry itself. Any response at all seems remarkable, because for many years the industry has shied away from making unsolicited public comments on health issues, partly out of fear of inadvertently making statements which could be used in the enormous personal injury suits which have been filed against them (Ernster, 1986). 
At present, however, the industry is divided on what public posture it should take. R. J. Reynolds has run full-page ads depicting the problem as one of "common courtesy" and "smokers' rights," rather than of health hazards. Philip Morris, on the other hand, has portrayed clean air advocates as dangerous zealots, who, in the words of its Vice-Chairman, could as easily attack "someone else's right to pray or choose a place to live. So the real issue isn't smoking versus non-smoking-it's discrimination versus tolerance." The fact that industry spokesmen are taking such an aggressive tack in public, after years of self-imposed silence, is impressive evidence of their deep concern about the success of anti-smoking and clean indoor air campaigns.

\section{WHY PASSIVE SMOKING IS AN IMPORTANT PUBLIC HEALTH CONCERN}

Passive smoking involves involuntary exposure of large numbers of people to an agent, cigarette smoke, which is well established as a cause of cancer in smokers and of other illnesses in non-smokers exposed to it. This agent contains high concentrations of known carcinogens. Therefore, even in the absence of epidemiologic evidence such exposure would be deemed potentially carcinogenic. Some epidemiologic studies, moreover, have shown lung cancer risk to be higher in women exposed to second-hand cigarette smoke. Such evidence is by no means unanimous or entirely consistent, but limitations inherent in epidemiological methods may make it impossible for us ever to be as certain about the health risks of passive smoking as we are about active smoking itself.

Many new studies of cancer risks from passive smoking are now in progress which take into account the problems encountered in earlier studies, and will undoubtedly lead to revision of the risk estimates made in those reports. It is unlikely, however, that the main conclusion (that an increased cancer risk exists) will be discarded; rather, it will probably be strengthened.

The consensus within the public health community is that it is neither necessary nor desirable to wait for "absolute proof" of causation, and that data now available justify acting on public health principles to limit, insofar as possible, public exposure to secondhand smoke. The legislative and other activities described in this paper are based upon these considerations. 
If the positive reports are indeed correct, the magnitude of the increase in risk for the non-smoker is on the order of 1.3 to 3.4 times the risk in the unexposed. Few case-control studies reported so far have had the very large sample size necessary to detect risks of this magnitude with reasonable statistical power, which may be an additional reason that some studies did not confirm an effect (Weiss, 1986). Even a fairly small relative risk, however, can translate into a large number of affected persons in a population as large as the United States. Repace and Lowrey, for example, have estimated that as many as 5,000 lung cancers per year which occur in non-smokers may be attributable to passive smoking (Repace and Lowrey, 1985).

Passive smoking should therefore be of special concern to non-smoking women who are married to smokers, or who work in an environment where others are permitted to smoke. In addition, women smokers should be aware of the health risks which they may create in the non-smokers they live and work with, and particularly the children they have or may be expecting.

\section{REFERENCES}

Ayer, H.E., \& Yeager, D.W, (1982). Irritants in cigarette smoke plumes. Am J Public Health 72:1283-1285.

Bonham, G.S., \& Wilson, R.W. (1981). Children's health in families with cigarette smokers. Am J Public Health 71:290-293.

Brunnemann, K.D., \& Hoffmann, D. (1978). Chemical studies on tobacco smoke. LIX. Analysis of volatile nitrosamines in tobacco smoke and polluted indoor environments. In E.A.Walker, L.Griciute, M.Castegnaro, R.E.Lyle, \& W.Davis (Eds.) Environmenial aspects of $N$-nitroso compounds. IARC Publ. No. 19 (pp. 343-356). Lyon, France: International Agency for Research on Cancer.

Butler, N.R., Goldstein, H., \& Ross, E.M. (1972). Cigarette smoking in pregnancy: Its influence on birth weight and perinatal mortality. Brit Med J 2:127-130.

Chan, W.C., \& Fung, S.C. (1982). Lung cancer in nonsmokers in Hong Kong. In Cancer Campaign, Vol. 6: Cancer Epidemiology. E. Grundmann, Ed. New York: Gustav Fischer Verlag.

Charlton, A. (1984). Children's coughs related to parental smoking. Brit Med J 288:16471649.

Comstock, G.W., Shak, F.K., Meyer, M.B., \& Abbey, H. (1971). Low birth weight and neonatal mortality rate related to maternal smoking and socioeconomic status. Am $J$ Obstet Gynecol 111:53-59.

Correa, P., Pickle, L.W., Fontham, E., Lin, Y., \& Haenszel, W. (1983). Passive smoking and lung cancer. Lancet 2:595-597.

Ernster, V.L. (1986). Women, smoking, cigarette advertising and cancer. Women and Health 11:217-235.

Friedman, G.D., Petitti, D.B., \& Bawol, R.D. (1983). Prevalence and correlates of passive smoking. Am J Public Health 73:401-405. 
Garfinkel, L. (1981). Time trends in lung cancer mortality among nonsmokers and a note on passive smoking. I Nall Cancer Inst 66:1061-1066.

Garfinkel, L., Auerbach, O.. \& Joubert, L. (1985) Involuntary smoking and lung cancer: A case-control study. J Narl Cancer Inst 75:463-469.

Goujard, J., Rumeau, C., \& Schwartz, D. (1975). Smoking during pregnancy, stillbirth and abruptio placentae. Biomedicine 23:20-22.

Greenberg, R.A., Haley, N.J., Etzel, R.A., \& Loda, F.A. (1984). Measuring the exposure of infants to tobacco smoke. Nicotine and cotinine in urine and saliva. New Engl J Med 310:1075-1078.

Harlap, S., \& Davies, A.M. (1974). Infant admissions to hospital and maternal smoking. Lancet 1:529-532.

Himmelberger, D.U., Brown, B.W., \& Cohen, E.N. (1978) Cigarette smoking during pregnancy and the occurrence of spontaneous abortion and congenital abnormality. $A m J$ Epidemiol 108:470-479.

Hirayama, T. (1981). Non-smoking wives of heavy smokers have a higher risk of lung cancer: A study from Japan. Brit Med J 282:183-185.

Hoffmann, D. Haley, N.J., Adams, J.D. \& Brunnemann, K.D. (1984). Tobacco sidestream smoke: Uptake by nonsmokers. Prev Med 13:608-618.

Jarvis, M.J., Russell, M.A.H., Feyerabend, D., Eiser, J.R., Morgan, M., Gammage, P., \& Gray, E.M. (1985). Passive exposure to tobacco smoke: Saliva cotinine concentrations in a representative population sample of non-smoking schoolchildren. Brit Med $J$ 291: 927-929.

Kabat, G.C., \& Wynder, E.L. (1984). Lung cancer in nonsmokers. Cancer 53:1214-1221.

Kauffmann, F., Tessier, J.F., \& Oriol, P. (1983). Adult passive smoking in the home environment: A risk factor for chronic airflow limitation. Am J Epidemiol 117:269-280.

Knight, A., \& Breslin, A.B.X. (1985). Passive cigarette smoking and patients with asthma. Med J Austral 142:194-195.

Koo, L.C., Ho, J.H.-C., \& Saw, D. (1983). Active and passive smoking among female lung cancer patients and controls in Hong Kong. $J$ Exp Clin Cancer Res 4:367-375.

Kornegay, H.R., Kastenbaum, M.A., Mantel, N., Harris, J.E., DuMouchel, W.H., Macdonald, E.J., \& Hirayama, T. (1983). Non-smoking wives of heavy smokers have a higher risk of lung cancer (letters to editor). Brit Med J 283:914-917.

Kullander, S., \& Kallen, B. (1971). A prospective study of smoking and pregnancy. Acta Obstet Gynecol Scand 50:83-94.

Lebowitz, M.D., \& Burrows, B. (1976). Respiratory symptoms related to smoking habits of family adults. Chest 69:48-50.

McIntosh, I.D. (1984). Smoking and pregnancy. II. Offspring risks. Public Health Rev 12:29-63.

Repace, J.L. (1984). Consistency of research data on passive smoking and lung cancer. Lancet 1:506.

Repace, J.L., \& Lowery, A.H. (1985). A quantitative estimate of nonsmokers' lung cancer risk from passive smoking. Environment International 11:3-22.

Rickert, W.S., Robinson, J.C., \& Collishaw, N. (1984). Yields of tar, nicotine, and carbon monoxide in the sidestream smoke from 15 brands of Canadian cigarettes. Am J Public Health 74:228-231.

Sandler, D.P., Everson, R.B., \& Wilcox, A.J. (1985a). Passive smoking in adulthood and cancer risk. Am J Epidemiol 121:37-48.

Sandler, D.P., Wilcox, A.J., \& Everson, R.B. (1985b). Cumulative effects of lifetime passive smoking on cancer risk. Lancet 1:312-314.

Schenker, M.B., Samet, J.M. . \& Speizer, F.E. (1983). Risk factors for childhood respiratory disease. The effect of host factors and home environmental exposures. Am Rev Resp Dis 128: 1038-1043.

Shephard, R.J., Collins, R., \& Silverman, F. (1979). Responses of exercising subjects to acute "passive" cigarette smoke exposure. Environ Res 19:279-291. 
Stein, Z. \& Kline, J. (1983). Smoking, alcohol, and reproduction. Am J Public Health 73:1154-1156, (editorial).

Trichopoulos, D., Kalandidi, A., Sparros, L., \& MacMahon B. (1981). Lung cancer and passive smoking. Int I Cancer 27:1-4.

Trichopoulos, D., Kalandidi, A., \& Sparros L. (1983). Lung cancer and passive smoking: Conclusion of Greek study. Lancet 2:678-679.

Trundle, J.I., \& Skellern, G.C. (1983). Gas chromatographic determination of nicotine in human breast milk. J Clin Hosp Pharmacol 8:289-293.

Tsokos, C.P., Macdonald, E.J., Lee, P.N., \& Hirayama, T. (1981). Non-smoking wives of heavy smokers have a higher risk of lung cancer (letters to editor). Brit Med J 283:14641466.

U.S. Department of Health, Education, and Welfare, (1979). Smoking and Health: A Report of the Surgeon-General. DHEW Publication No. (PHS) 79-50066. USDHEW. Public Health Service, Office on Smoking and Health, pp. 11-6 to 11-24.

U.S. Deparment of Health and Human Services. (1980). The Health Consequences of Smoking For Women: A Report of the Surgeon-General. USDHHS. Public Health Service, Office on Smoking and Health.

Ware, J.H., Dockery, D.W., Spiro, A., Speizer, F.E., \& Ferris, B.G. (1984). Passive smoking, gas cooking, and respiratory health of children living in six cities. Am Rev Resp Dis $129: 366-374$.

Weber, A. (1984). Annoyance and irritation by passive smoking. Prev Med 13:618-625.

Weiss, S.T. (1986). Passive smoking and lung cancer. What is the risk? Am Rev Resp Dis 133:1-3.

Winn, D.M., \& Pickle, L.W. (1986). Smokeless tobacco and cancer in women: Implications for cancer research. Women and Health 11:253-266.

Wu, A.H., Henderson, B.E., Pike, M.C., \& Yu, M.C. (1985). Smoking and other risk factors for lung cancer in women. $J$ Natl Cancer inst 74:747-75I. 